\title{
O IMPACTO CAUSADO PELA FALTA DA COMPATIBILIZAÇÃO ENTRE PROJETOS DE UMA EDIFICAÇÃO HOSPITALAR
}

\author{
SANTANA, DIEGO DOS SANTOS \\ Graduado em Engenharia Civil \\ Universidade Federal da Bahia \\ Bahia; Brasil \\ diego_santana1@hotmail.com
}

\author{
Mestranda em Engenharia Civil \\ Universidade Federal da Bahia \\ Bahia; Brasil \\ lubastosb@gmail.com
}

BARBOSA, LUANNE BASTOS DE BRITTO

\author{
COELHO, VINÍCIUS ALMEIDA \\ Mestrando em Engenharia Civil \\ Universidade Federal da Bahia \\ Bahia; Brasil \\ mrvoelho@gmail.com
}

\author{
MARTINS, MATHEUS GOMES \\ Mestrando em Engenharia Civil \\ Universidade Federal da Bahia \\ Bahia; Brasil \\ matheus.engmartins@gmail.com
}

\author{
CERQUEIRA, MILENA BORGES DOS SANTOS SILVA, FRANCISCO GABRIEL \\ SANTOS \\ Doutoranda em Engenharia Civil \\ Universidade Federal da Bahia \\ Bahia; Brasil \\ milena.bsc@gmail.com \\ Professor Doutor \\ Universidade Federal da Bahia \\ Bahia; Brasil \\ fgabriel.ufba@gmail.com
}

\begin{abstract}
RESUMO
Os problemas de compatibilização entre projetos da construção civil, em especial nos hospitais, geram diversos entraves para o pleno funcionamento dessas instituições. A ineficiência da prestação dos serviços assistenciais devido aos problemas de compatibilização de projetos, gera prejuízo em todo o ciclo do serviço hospitalar, em especial na esfera pública que padece com os custos e prazos adicionais. Nesse contexto, surge a necessidade de analisar e identificar as principais incompatibilidades, a fim de buscar soluções que garantam uma otimização das construções e sua manutenibilidade. O objetivo geral deste trabalho baseia-se em analisar a importância da compatibilização entre projetos da construção civil aplicado em um hospital público localizado na cidade de Salvador - BA, por meio da caracterização das disciplinas e análise dos projetos. Não obstante a isso, foram apresentados diversos pontos de interferência, colaborando para que os Gestores Públicos da área hospitalar sejam sensibilizados quanto a importância do processo de compatibilização ainda na fase de concepção dos empreendimentos, prevendo e evitando possíveis danos à fase de execução e uso, assim como o funcionamento seguro dos sistemas hospitalares ao longo da sua vida útil. Palavras-chave: compatibilização de projetos, gestão pública, patologia, desempenho.
\end{abstract}

\section{ABSTRACT}

The problems of compatibility between construction projects, especially in hospitals, generate various obstacles to the full functioning of these institutions. The inefficiency of the provision of care services due to the problems of compatibility of projects, generates damage throughout the hospital service cycle, especially in the public sphere that suffers from additional costs and deadlines. In this context, the need arises to analyze and identify the main incompatibilities, in order to seek solutions that guarantee an optimization of buildings and their maintainability. The general objective of this paper is to analyze the importance of compatibility between construction projects applied in a public hospital located in the city of Salvador - BA, through the characterization of disciplines and analysis of projects. Notwithstanding this, several points of interference were presented, helping the Public Managers of the hospital area to be sensitized as to the importance of the compatibilization process still in the project conception phase, foreseeing and avoiding possible damages to the execution and use phase, as well as the safe operation of hospital systems over their lifetime.

Keywords: compatibility of project, public administration, pathology, performance. 


\section{INTRODUÇÃO}

A construção civil vem recebendo um aprimoramento tecnológico em busca da otimização dos processos, por meio de ganhos de eficiência, redução do desperdício e melhor qualificação dos empreendimentos. Para as empresas da construção civil obterem vantagens competitivas, é primordial que o planejamento seja bem executado e que os projetos estejam adequados e compatibilizados, pois, quando isso não acontece observam-se interferências entres os projetos, que consomem recursos e diminuem a competitividade (SANTOS; BRANCO; FILHO, 2013).

Apesar dos avanços tecnológicos, a falta de informações muitas vezes faz com que seja necessário admitir arbitrariamente alguns dados de projeto, visando dar continuidade ao processo. Com frequência, essas decisões não são verificadas posteriormente, fato que resulta em retrabalhos, erros de projeto ou de execução. Parte da melhoria do projeto é baseada na eliminação deste retrabalho, através da redução das incertezas na fase inicial do processo, por meio de um escopo de projeto bem definido e consideração de todo ciclo de vida útil da edificação (TZORTZOPOULOS, 1999).

Corroborando com isso, Tzortzopoulos, Chan e Cooper (2005) relatam que a realização adequada de projetos em ambientes hospitalares sejam capazes de contribuir para melhores resultados terapêuticos. Além disso, projetos de empreendimentos da saúde reemergiram como foco de debate sobre terapia, tendo em vista os desafios para entregar edifícios de alta qualidade, que acomodem com sucesso intervenções clínicas e tecnologias médicas complexas, ao mesmo tempo em que forneçam ambientes mais humanos (TZORTZOPOULOS; CHAN; COOPER, 2005).

Hospitais são organizações complexas, desde a sua concepção até utilização. $\mathrm{O}$ zoneamento de atividades facilita a circulação de pessoas e processos evitando o cruzamento de fluxos de trabalho, materiais e insumos, que acabam por prejudicar a produtividade ou se tratando de um ambiente hospitalar, colocar em risco os colaboradores e os pacientes. Portanto, na gestão do projeto deve-se estudar e projetar edificações que atenda os fluxos hospitalares e a orientabilidade nos edifícios.

Assim sendo, a complexidade da execução de ambientes hospitalares induz a necessidade de aprimoramento nos métodos e ferramentas, que viabilizem melhores soluções de projeto, de maneira, a possibilitar um melhor atendimento assistencial, bem como de projetos adequados às especificações que os serviços hospitalares exigem. Atrelado a isso, está o uso de ferramentas que auxiliam na compatibilização e gerenciamento, possibilitando a tomada de decisões em busca da satisfação dos usuários, minimizando a probabilidade de ocorrência de problemas e os impactos gerados por falhas durante as etapas de vida útil do projeto.

O desenvolvimento de projetos consiste na interação entre os diversos projetistas, desde da etapa inicial, para que os problemas sejam identificados e solucionados o mais breve possível (MELHADO e MELHADO, 2009). Segundo Melhado e Melhado (2009), sempre existe a possibilidade de discrepâncias ou incoerências entre os projetos, e na compatibilização tais problemas são evidenciados para que a coordenação possa agir sobre eles e solucioná-los.

Uma das consequências da falta de compatibilização entre os projetos é o surgimento de manifestações patológicas, tendo suas origens motivadas por falhas que ocorrem durante a realização de uma ou mais das atividades inerentes ao processo, típicos da construção civil, processo este que pode ser dividido em três etapas básicas: falhas de projeto, execução e de manutenção.

Portanto, é fundamental que os gestores do hospital se atentem para a importância da análise prévia dos projetos, de modo a entender as informações necessárias para que os projetistas e os responsáveis pelas análises dos projetos tenham um embasamento teórico e uma referência prática, das especificidades de uma reforma e ampliação de um hospital público, quanto ao desenvolvimento de projetos.

Deste modo, o presente trabalho propõe demonstrar a importância da compatibilização de projetos na obra de reforma e ampliação do Hospital em estudo, inclusive identificando as principais interferências encontradas, com o intuito de promover um embasamento teórico aos gestores públicos sobre a importância da análise dos projetos de maneira multidisciplinar, de forma, que as obras públicas apresentem uma melhor conformidade, otimização e durabilidade. 


\section{METODOLOGIA}

Foi elaborada uma pesquisa descritiva, por meio de um estudo de caso num hospital público localizado em Salvador BA. Para tanto, foram realizadas visitas técnicas e coleta de dados necessários, por meio de registro fotográfico, para o levantamento das interferências existentes entre os projetos.

O estudo de caso em questão, foca na compatibilização entre os projetos desenvolvidos para a execução da reforma e ampliação do hospital, a fim de evidenciar algumas interferências encontradas entre os projetos; e entre os projetos e as condições de contorno. Para a elaboração do trabalho foram utilizados fotos, projetos arquitetônicos e complementares, os quais foram cedidos pelo hospital maternidade para fins acadêmicos.

A partir de então, através do acervo fotográfico e dos projetos arquitetônico e complementares, foram feitas análises das principais interferências identificadas entre os projetos de cada disciplina, de modo a constatar o panorama geral da obra em estudo quanto ao processo projetual.

No trabalho de compatibilização foi definido previamente uma sequência lógica na análise dos dados, algumas etapas foram seguidas para tornar mais compreensível. Num primeiro momento foram caracterizadas as disciplinas com maior incidência de interferências, apresentando os materiais utilizados e os métodos de identificação das incompatibilidades, em seguida foram expostas os resultados e discussões acerca das interferências entre as disciplinas de estrutura, arquitetônico e hidrossanitário e; climatização, gases medicinais, hidrossanitário e elétrico. Para fins de simplificação, as áreas de reforma e ampliação foram analisadas em conjunto.

\section{RESULTADOS E DISCUSSÕES}

\subsection{Caracterização da edificação}

O Hospital em estudo faz parte da rede de hospitais universitário da EBSERH e fica localizado em um Bairro do Centro de Salvador, Bahia. Trata-se de um hospital público de construção centenária, em que ocupa uma área de pouco mais de $5000 \mathrm{~m}^{2}$, composta por 5 (cinco) blocos com 2 (dois) pavimentos cada um, com exceção do Centro Obstétrico que possui apenas 1 (um) pavimento. As características das edificações do hospital demonstram que foram sofridas ampliações e adaptações ao longo de sua existência, apesar de não existir projetos destas alterações. A estrutura do prédio é de maneira hibrida, sendo que alguns blocos apresentam estrutura em concreto armado e outros são compostos por alvenaria estrutural, parte construída com alvenaria de pedra e parte com tijolos maciços. Em alguns trechos, é possível identificar a existência de lajes maciças em concreto armado e em lajes pré-moldadas treliçadas.

As fachadas apresentam em alvenarias de bloco cerâmico e em alvenaria de pedra, mantendo as características originais da construção. O piso da edificação é o de alta resistência de concreto desempenado, na área interna, possuindo revestimento de placas cerâmicas somente em banheiros e áreas molhadas. A estrutura da cobertura é de madeira com telhas de fibrocimento na metade dos blocos e telha termo acústica na outra metade.

Com os dados coletados, verifica-se que a edificação vem passando por reformas, sendo que, o principal objeto deste estudo, o Centro Obstétrico e PP - Pré Parto, estão sofrendo adequações dos fluxos e dos sistemas de instalações prediais.

\subsection{Compatibilização entre os projetos}

Durante a execução da obra foram observados diversos problemas construtivos, os quais poderiam ter sido identificados ainda na fase projetual. Essas interferências envolveram todas as disciplinas dos projetos, estrutural, arquitetônico, climatização e outros. Como consequência, surgem retrabalhos, atrasos de serviços, dilação do cronograma inicial, aumento de custo e diversos transtornos que acompanha as situações. As falhas são descritas a seguir.

Inicialmente, cabe salientar que durante análise do projeto da reforma, obteve-se diversos indícios que não foi feita uma compatibilização do projeto arquitetônico com a forma estrutural existente (paredes portantes), pois o projetista previu a demolição de algumas paredes do prédio existente sem avaliar as condições estruturais, e devido este fato, para adequar a edificação foi necessário a realização de alterações no projeto arquitetônico, com a consequente adição de projeto de reforço metálico nos pontos necessários durante a execução da obra, acarretando em incremento de custos e atrasos no prazo inicial. Na Figura 1 é apresentada a execução in loco. 


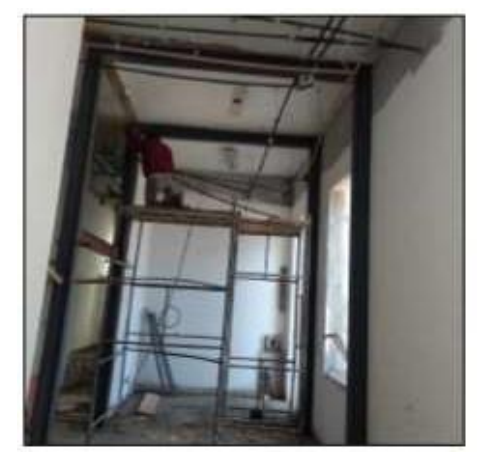

Figura 1: Execução de reforço metálico durante a obra

Já no caso da elaboração dos projetos do trecho de ampliação do prédio (construção nova), o projetista não se atentou para as interferências com a edificação existente, nem com a rede elétrica subterrânea, os quais passavam dutos e cabos elétricos energizados que vinham direto da subestação, ficando claro que além de não haver uma compatibilização dos projetos estruturais, houve negligência quantos aos aspectos da avaliação das condições de contorno, o que acarretou diversas interferências na fundação, revisões de projetos, aumento de custo, dilação do cronograma, retrabalhos e desgaste da equipe. Algumas dessas situações são mostradas abaixo nas Figuras 2 e 3:

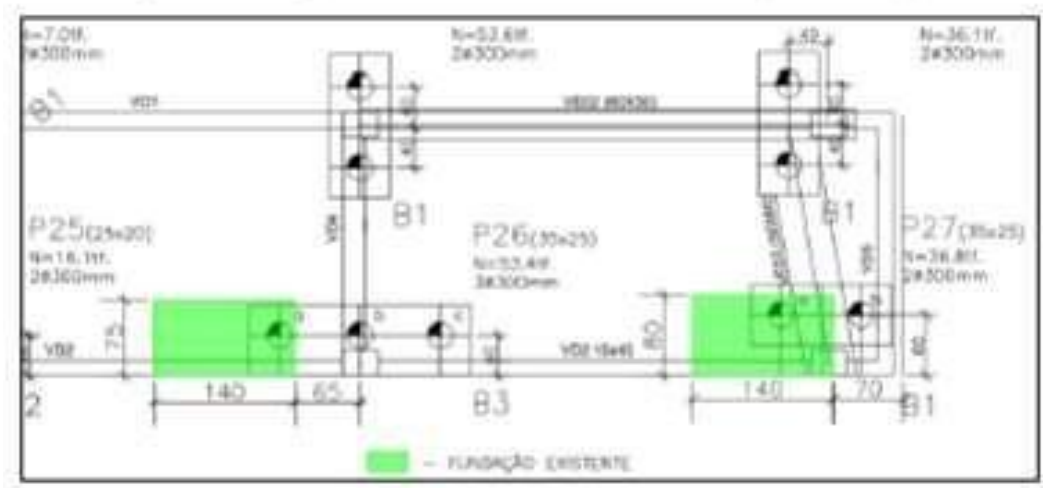

Figura 2: Execução de reforço metálico durante a obra

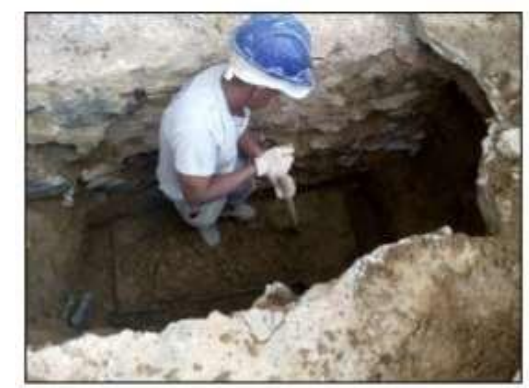

Figura 3: Prospecção da edificação vizinha na fase de execução

A prospecção mostrada na Figura 3 deveria ter sido feita na fase de concepção do projeto de fundações, assim as chances de interferência com as condições de contorno teriam sido amenizadas.

Nas Figuras 4 e 5, é apresentada a situação da alimentação elétrica, que por ser subterrânea, não foi feita uma pesquisa, nem compatibilização com o projeto estrutural. Como a ligação estava alimentada por corrente elétrica, foram tomadas algumas medidas de segurança e uma atenção maior na execução da estrutura nas suas redondezas, o que proporcionou atraso do serviço. 


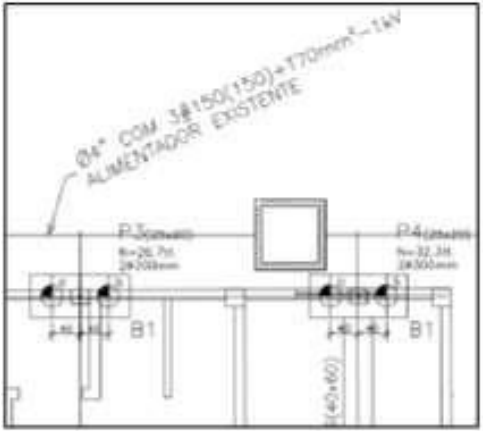

Figura 4: Alimentador elétrico predial ao lado dos blocos de estacas

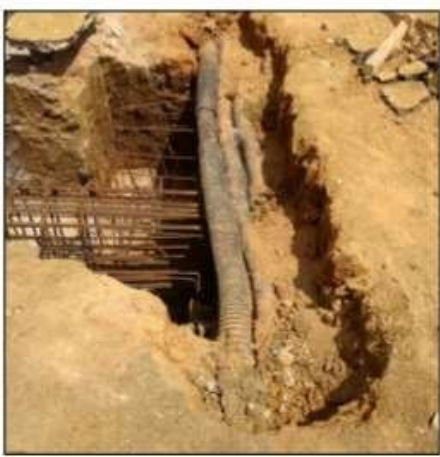

Figura 5: Interferência do cabeamento elétrico no desenvolvimento da estrutura

Por meio das imagens fica clara a dificuldade de execução das armaduras dos blocos de fundação, além de atividades inerentes a situação, como uma maior atenção e planejamento.

Nas Figuras 6 e 7 verifica-se, em alguns trechos, que boa parte da seção das vigas do pavimento térreo ficou comprometida devido aos tubos do esgotamento sanitário, o que poderia já ter sido avaliado pela equipe de projetos, inclusive já prevendo e dimensionando estes "furos|" no projeto, garantindo a segurança, durabilidade e desempenho da estrutura.

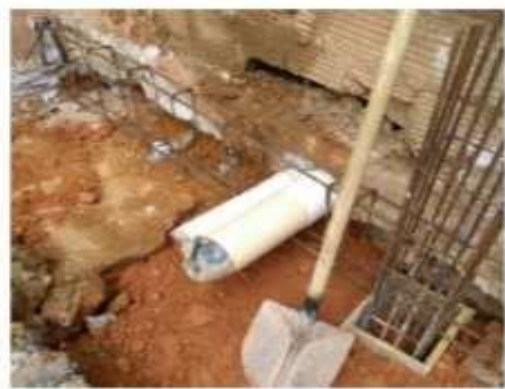

Figura 6: Interferência entre o sistema estrutural e sanitário

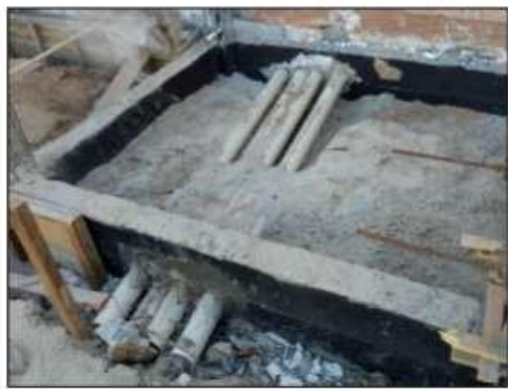

Figura 7: Interferências entre o sistema estrutural e sanitário

Concomitantemente a isso, foram encontradas incompatibilidades entre a estrutura e a concepção do projeto elétrico, principalmente no que se refere a furos em vigas, os quais não foram previstos no escopo inicial do projeto e acabaram sendo executados de maneira indevida por parte da Construtora, tendo em vista que foram realizados sem a devida consulta e avaliação do projetista estrutural, podendo gerar uma redução na capacidade portante da estrutura. Sendo assim, da mesma forma que as vigas do térreo ficaram comprometidas devidos aos tubos do esgotamento, as vigas do pavimento superior foram prejudicadas pela passagem dos eletrodutos. Nas Figuras 8 e 9 é possível notar algumas dessas intervenções.

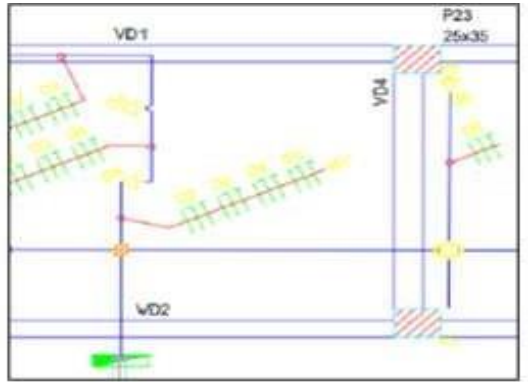

Figura 8: Interferência do sistema elétrico com estrutural em planta

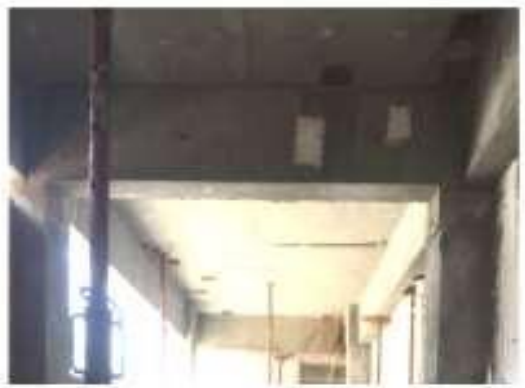

Figura 9: Furos em vigas para passagem de eletrodutos 
As incompatibilidades com o projeto estrutural também foram encontradas nos furos, os quais foram realizados para passagem de eletrocalhas, eletrodutos e rede de ar condicionado, sem que houvesse a contemplação de avaliação de reforço da estrutura em todos os pontos.

Não obstante a isso, o projetista não contemplou as interferências relacionadas às dimensões dos equipamentos a serem instalados com o pé-direito da estrutura, o que inviabilizava a instalação dos mesmos, tendo em vista que a altura ocupada ficava inviável para ocupação das pessoas e altura do forro a ser instalado.

Foram encontradas incompatibilidades dos projetos de climatização com os de águas (hidrossanitário) e elétrico de uma forma recorrente. Para realizar a compatibilização da Figura 10, foi feita a sobreposição do projeto de climatização com o projeto de águas. As interferências então em foco pelo círculo azul claro.

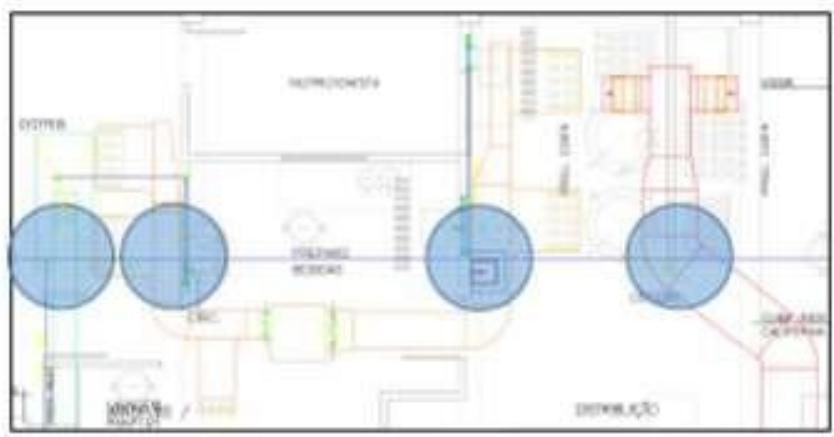

Figura 10: Algumas incompatibilidades no projeto de climatização com o hidrossanitário

Conforme visto na Figura 10, em apenas um ambiente, diversas interferências foram encontradas, o que pode acarretar em uma considerável mudança na concepção e desenvolvimento do projeto, o que é capaz de tornar a nova solução muito mais cara do que a inicialmente proposta. Uma dessas interferências sinalizadas na Figura 10 pode ser vista na Figura 11.

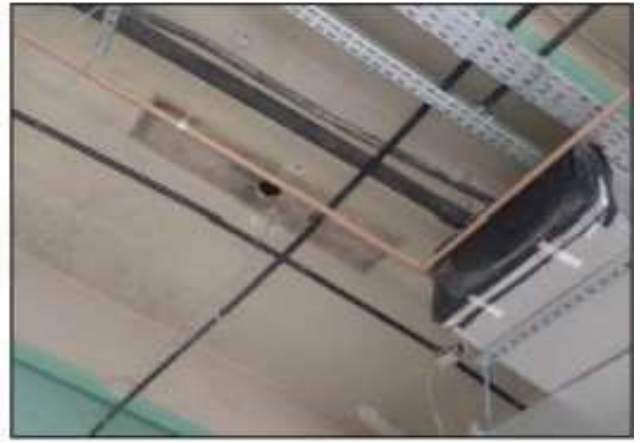

Figura 11: Uma interferência no projeto de climatização com do projeto de águas

Na elaboração dos projetos do hospital em estudo, além das leis e normas, os projetistas tiveram uma complexidade maior por se tratar de uma instituição centenária.

A obra em estudo sofreu uma alteração significativa do prazo inicial, para mais, em grande parte decorrente das interferências entre os projetos. Por se tratar de um hospital maternidade, o impacto a sociedade é ainda maior do que as demais construções públicas, pelo fato de desenvolver um serviço essencial para a capital baiana e região metropolitana.

Verificou-se que os projetos desenvolvidos para a execução da obra em análise, foram desenvolvidos de forma sequencial, sem uma compatibilização simultânea durante o desenvolvimento. Com isso, a integração entre as disciplinas ficou comprometida, acarretando em diversas interferências, as quais, algumas foram mostradas no desenvolvimento do presente trabalho.

A problemática poderia ter sido amenizada com a presença de um coordenador de projetos, por parte do escritório responsável, inclusive verificando e validando os projetos antes da entrega ao contratante, bem como a existência de uma fiscalização mais efetiva, por parte do cliente, no recebimento definitivo do produto. 
Devido as interferências encontradas nos projetos, na execução da obra foram encontrados grandes conflitos entre a parte estrutural e os projetos complementares. Tal situação já surgiu desde a fundação do prédio novo, em que foi necessário a revisão do projeto, ocasionando um certo atraso por parte da empresa responsável para revisar e apresentar uma solução, o que acabou interferindo no cronograma desde do início da execução.

Durante o desenvolvimento do trabalho, algumas compatibilizações foram feitas da mesma forma como foi realizada a compatibilização em campo, com a sobreposição das pranchas 2D do tipo CAD (Desenho Assistido por Computador), mas essa prática não é a mais adequada, já que os avanços tecnológicos hoje permitem o uso de softwares com desenhos tridimensionais, em que as disciplinas se comunicam. A tecnologia BIM (Building Information Model), permite a identificação de interferências de uma forma muito otimizada e de fácil interação, quando bem fornecido os parâmetros do sistema, hoje tem-se exemplos de softwares com uso de BIM usado em larga em escala como o software REVIT. Importante frisar que para o uso de BIM na obra em estudo, toda a concepção e desenvolvimento do projeto deveria ter sido feita sob esta ótica.

A esfera pública muitas vezes desconsidera a exigência do uso da ferramenta BIM nas licitações para elaboração dos projetos e orçamentos das obras, o que mitigaria os riscos de projetos básicos e executivos ineficientes e incompletos.

De forma geral, aconteceram diversas interrupções de serviços na construção do edifício devido as incompatibilidades que surgiram na execução da obra, em grande parte devido a uma compatibilização ineficiente na fase de projetos. Com isso, foram feitas diversas revisões com o escritório responsável pela elaboração dos projetos, custando tempo, mão de obra e interferência no funcionamento do hospital.

Por ser uma maternidade, a intuição possui um papel social fundamental, atrasos como os que aconteceram compromete o bem-estar da população, pode dificultar atendimentos, além de ser custoso para os cofres públicos devido os altos alugueis que são pagos para manter o hospital em outra localidade, mesmo que parcialmente. Em suma, a compatibilização por planta em 2D compromete a interpretação das interferências, deixando que algumas incompatibilidades sejam percebidas no início da execução, ou depois delas; boa parte desses percalços podem ser evitados com o uso de soluções 3D em BIM, além de uma análise prévia das condições de contorno na fase de concepção do projeto, atrelados com uma análise crítica no recebimento dos projetos.

\section{CONCLUSÕES}

Por meio das análises realizadas acerca da compatibilização dos projetos envolvidos no empreendimento estudado, foi possível evidenciar o tema da compatibilização de projetos e sua importância para gestão da obra e a partir desse ponto os gestores públicos podem tomar medidas acerca do cronograma, da solução proposta para os projetos, da concepção da licitação e outros encaminhamentos que vão gerar menos retrabalho, menores custos e uma otimização de forma geral do empreendimento a ser desenvolvido.

Foi possível observar que a grande deficiência na elaboração dos projetos, atrelada à execução inadequada por parte da construtora, está relacionada principalmente à problemas de compatibilização de projetos e da falta de estudos preliminares na elaboração, o que proporciona uma perda de qualidade, aumento de custo e dilação do prazo de execução, consequentemente trazendo danos ao Erário.

No caso de construções antigas e centenárias, que é o caso do hospital em estudo, a redução natural na resistência dos materiais empregados provoca deterioração, agravada pela ação climática agressiva. Contudo, a predisposição da estrutura, ou de uma de suas partes, em apresentar manifestações patológicas foi originada durante a fase de projeto, de construção, e também adquirida na fase de uso.

Ficou demonstrado que a sobreposição dos desenhos em 2D é uma alternativa que é possível de ser utilizada na compatibilização dos projetos, mas devidos a conjuntura atual não é a melhor solução, hoje tem-se soluções como a tecnologia BIM, que permite analisar de forma otimizadas as interferências e incompatibilidades entre os projetos; ao ponto que são fornecidos e preenchidos os parâmetros de forma adequada para o software que utiliza a tecnologia.

De forma geral o presente trabalhou fornece informações necessárias para que os projetistas e os responsáveis pelas análises dos projetos, tenham um embasamento teórico e uma referência prática das especificidades de uma reforma e ampliação de um hospital público, quanto ao desenvolvimento de projetos, ao ponto que fornece os critérios necessários. 


\section{AGRADECIMENTOS}

Agradecemos à Fundação de Amparo à Pesquisa do Estado da Bahia (FAPESB) pelo apoio fincanceiro e incentivo à pesquisa.

\section{REFERÊNCIAS}

MELHADO, ANA ROCHA; MELHADO, SILVIO. Gestão do processo de projeto. 2009.

SANTOS, WHITE JOSÉ DOS; BRANCO, LUIZ ANTÔNIO MELGAÇO NUNES; FILHO, JÚLIO VALTER DE ABREU. Compatibilização de Projetos: Análise de algumas falhas em uma Edificação Pública. In: CONGRESSO NACIONAL DE EXCELENCIA EM GESTÃO, JUNHO, 9. Niterói, RJ. 2013.

TZORTZOPOULOS, PATRÍCIA. Contribuições para o desenvolvimento de um modelo do processo de projeto de edificações em empresas construtoras incorporadoras de pequeno porte. Porto Alegre, v. 163, 1999.

TZORTZOPOULOS, PATRÍCIA; CHAN, PAUL; COOPER, RACHEL. Requirements management in the design of primary healthcare facilities. In: Simpósio Brasileiro de Gestão e Economia de Construção. 2005. 